\title{
Otimização das condições de cultivo para a produção de amilases pelo termofílico Bacillus sp. e hidrólise de amidos pela ação da enzima
}

\author{
Optimization of culture conditions for the production of amylases by thermophilic \\ Bacillus sp. and hydrolysis of starches by the action of the enzymes
}

\author{
Raquel Vieira de CARVALHO ${ }^{1}$, Thamy Lívia Ribeiro CORRÊA ${ }^{1}$, Júlia Caroline Matos da SILVA \\ Alexandre Pio VIANA ${ }^{1}$, Meire Lelis Leal MARTINS ${ }^{1 *}$
}

\section{Resumo}

A otimização das condições de cultivo para a produção de $\alpha$-amilase por um termofílico Bacillus sp. cepa SMIA-2 foi realizada. Além disso, a hidrólise enzimática do amido, proveniente de várias fontes tais como batata, mandioca e milho, foi também investigada. A produção de $\alpha$-amilase por Bacillus sp. SMIA-2, cultivado em meio líquido contendo amido ( 5 g. $\left.\mathrm{L}^{-1}\right)$ como fonte de carbono e suplementado com 0,5 g.L ${ }^{-1}$ de proteínas do soro de leite e 2 g. $\mathrm{L}^{-1}$ de peptona, alcançou o máximo em 32 horas com níveis de $37 \mathrm{U} \cdot \mathrm{mL}^{-1}$. O microrganismo foi capaz de utilizar diversas fontes de carbono, porém a atividade da amilase variou com cada fonte. O amido foi a melhor fonte de carbono para a secreção da amilase, enquanto a sacarose, lactose, maltose, galactose e glicose não foram muito efetivas. Uma redução na concentração de amido de até 2,5 g. $\mathrm{L}^{-1}$ no meio de cultura melhorou o crescimento do organismo e a atividade enzimática. Em altas concentrações de amido, a produção da enzima foi comparativamente menor. Em relação às fontes de nitrogênio orgânico e inorgânico, a peptona $\left(2\right.$ g. $\left.L^{-1}\right)$ foi considerada a melhor. Considerando a quantidade de proteínas do soro de leite no meio de cultivo, a concentração de 0,25 g. $\mathrm{L}^{-1}$ foi considerada a mais efetiva para a secreção da $\alpha$-amilase pelo microrganismo. A produção máxima da atividade enzimática foi observada a $50{ }^{\circ} \mathrm{C} \mathrm{e} \mathrm{pH} \mathrm{8,5.} \mathrm{A} \mathrm{enzima} \mathrm{foi} \mathrm{capaz} \mathrm{de} \mathrm{degradar} \mathrm{todos} \mathrm{os} \mathrm{amidos} \mathrm{testados.} \mathrm{A} \mathrm{hidrólise} \mathrm{do} \mathrm{amido} \mathrm{de} \mathrm{batata} \mathrm{resultou} \mathrm{num} \mathrm{alto} \mathrm{rendimento} \mathrm{de}$ açúcares redutores em comparação às outras fontes de amido. Amido solúvel e amido de mandioca ocuparam, respectivamente, a segunda e terceira posição em relação à liberação dos açúcares redutores, enquanto que a amilase estudada mostrou apenas uma ligeira afinidade pelo amido de milho. Com o aumento da temperatura da reação para $70^{\circ} \mathrm{C}$, a hidrólise dos substratos, com exceção do amido solúvel, resultou em maiores quantidades de açúcares redutores.

Palavras-chave: amilase; Bacillus; amido; hidrólise; bactéria termofílica.

\begin{abstract}
The optimization of culture conditions for the production of $\alpha$-amylase by the thermophilic Bacillus sp strain SMIA-2 was carried out. In addition, the enzymatic hydrolysis of starch from several sources, such as potato, cassava and corn was investigated. Alpha-amylase production by Bacillus sp SMIA-2 cultivated in liquid cultures containing starch as carbon source and supplemented with 0.5 g. $\mathrm{L}^{-1}$ whey protein and 2.0 g. $\mathrm{L}^{-1}$ peptone reached a maximum of $37 \mathrm{U} \cdot \mathrm{mL}^{-1}$ at 32 hours. The microorganism was capable of utilizing several carbon sources, but amylase activity varied with each source. Starch was the best carbon source for amylase secretion, while lactose, maltose, sucrose, galactose, and glucose were not very effective. Decreasing starch concentration in the medium to 2.5 g. $\mathrm{L}^{-1}$ improved organism growth and enzyme activity. At higher starch concentrations, enzyme production was comparatively lower. Among the various organic and inorganic nitrogen sources, peptone ( 2.0 g.L. $\left.\mathrm{L}^{-1}\right)$ was found to be the best. Regarding the amount of whey protein in the medium, the concentration of 0.25 g. $\mathrm{L}^{-1}$ was considered the most effective for amylase secretion by the organism. Maximum amylase activity was observed at $50{ }^{\circ} \mathrm{C}$ and $\mathrm{pH} 8.5$. The enzyme was able to degrade all the starches tested. Potato starch hydrolysis resulted in a higher yield of reducing sugars in comparison to the other starches. Soluble and cassava starch were, respectively, in second and third positions regarding the liberation of reducing sugars, while the amylase studied showed a slightly lower affinity for corn starch. Increasing the reaction temperature to $70{ }^{\circ} \mathrm{C}$ resulted in higher levels of reducing sugars after the hydrolysis of the substrates, except for soluble starch.

Keywords: amylase; Bacillus; starch; hydrolysis; thermophilic bacterium.
\end{abstract}

\section{Introdução}

As amilases constituem um dos mais importantes grupos de enzimas industriais com aplicações em diferentes indústrias como de alimentos, têxtil, química, farmacêutica e de detergentes (DEMIRKAN et al., 2005; GUPTA et al., 2003; NIELSEN; BORCHERT, 2000; PANDEY et al., 2005; SOCCOL, 2005; SURMELY, 2003).
As enzimas amilolíticas são responsáveis por 25 a 33\% da produção mundial de enzimas, ocupando segundo lugar logo após as proteases (NGUYEN et al., 2002). Dentre estas, a mais importante é a $\alpha$-amilase, pois desempenha um papel fundamental na conversão do amido em produtos de baixo peso molecular, que podem ser utilizados por outras enzimas do

Recebido para publicação em 31/1/2007

Aceito para publicação em 10/9/2007 (002245)

Centro de Ciências e Tecnologias Agropecuárias, Universidade Estadual do Norte Fluminense - UENF, Av. Alberto Lamego, 2000, CEP 28015-620,

Campos dos Goytacazes - RJ, Brasil,E-mail:meire@uenf.br

${ }^{*}$ A quem a correspondência deve ser enviada 
mesmo grupo. É desejável que a $\alpha$-amilase seja ativa em altas temperaturas para a gelatinização $\left(100-110^{\circ} \mathrm{C}\right)$ e para liquefação (80-90 ${ }^{\circ} \mathrm{C}$ ) do amido (PEIXOTO et al., 2003; SARIKAYA et al., 2000; SIDHU et al., 1997).

As amilases produzidas por microrganismos termofílicos têm recebido considerável atenção da indústria por serem termoresistentes e por possuírem características importantes como estabilidade à temperatura e ao $\mathrm{pH}$. Entre as $\alpha$-amilases bacterianas mais importantes industrialmente, estão as secretadas pelo gênero Bacillus. Das 48 espécies de Bacillus descritas, 32 produzem $\alpha$-amilase, mas apenas poucas destas são capazes de secretar enzimas ativas em altas temperaturas. Dentro deste gênero, B. amyloliquefaciens, B. stearothermophilus, B. subtilis e $B$. licheniformis são as duas espécies mais utilizadas freqüentemente na produção comercial de $\alpha$-amilase (SAJEDI et al., $2005)$. As vantagens em se usar $\alpha$-amilase termoestável em processos industriais incluem diminuição do risco de contaminação, aumento da taxa de difusão dos reagentes e diminuição dos custos com refrigeração externa (LIN; CHYAU; HSU, 1998).

Alguns microrganismos produzem uma quantidade limitada de enzimas dificultando sua aplicação industrial. Porém, na maioria dos casos, adotando-se métodos simples como a utilização de um meio de cultura específico e otimizado é possível aumentar significativamente o rendimento enzimático (KUMAR; TAKAGI, 1999). A produção industrial de enzimas é freqüentemente limitada devido aos custos dos substratos utilizados para o cultivo dos microrganismos. Estima-se que por volta de 30 a $40 \%$ do custo envolvido na produção de enzimas esteja relacionado ao meio de cultura utilizado para o crescimento do microrganismo. Portanto, sua otimização é de grande importância para a redução dos custos de produção (JOO; CHANG, 2005).

Amido e amiláceos foram descritos como os substratos mais adequados para a alta produtividade de amilases (ALI; HOSSAIN, 1991; GOSH; CHATTERJEE; DAS, 1991; KILIKIAN, 1996), podendo ser aproveitados resíduos agrícolas ou de processamento de amido, os quais contêm quantidades residuais de amido suficientes para esse fim (DJEKRIF-DAKHMOUCHE et al., 2006; HAQ et al., 2003; KONSULA; LIAKOPOULOU-KYRIAKIDES, 2004).

Vários resíduos agroindustriais são usados como fontes alternativas de substratos para a produção de enzimas (BOCCHINI et al., 2005), devido à disponibilidade local e por representar uma fonte alternativa de baixo valor comercial, principalmente quando se visa à produção destas enzimas em larga escala. De modo geral, a preocupação em relação à utilização mais eficiente de resíduos agroindustriais vem aumentando a cada ano. Resíduos como o soro de queijo, altamente rico em proteínas, tem sido utilizado por diversos pesquisadores (BAJPAI; BAJPAI, 1989; NASCIMENTO; MARTINS, 2004; ROMERO et al., 2001; USTÁRIZ et al., 2004; WU et al., 2006).

Apesar de existir um bom número de trabalhos sobre a produção e as propriedades de $\alpha$-amilases bacterianas, as informações apresentadas na maioria dos casos dificilmente podem ser generalizadas para diferentes linhagens. Isto se deve ao fato de que os diferentes microrganismos se comportam de maneira variada frente a uma mesma condição de incubação, podendo produzir enzimas com propriedades diversas.

O objetivo deste trabalho foi otimizar a produção de amilase pelo termofílico Bacillus sp. SMIA-2 utilizando substratos de baixo custo. Além disso, avaliou-se a eficiência da enzima em hidrolisar vários tipos de amido.

\section{Material e métodos}

\subsection{Microrganismo e condições da cultura}

O microrganismo utilizado neste estudo foi uma bactéria termofílica, Bacillus sp. SMIA-2, previamente isolada de amostras de solo e coletada na cidade de Campos dos Goytacazes, Rio de Janeiro, Brasil (NUNES; MARTINS, 2001).

Para a produção da amilase o seguinte meio de cultura foi utilizado (g.L $\mathrm{L}^{-1}$ de água destilada): amido solúvel - 5,0; proteínas do soro de leite - 0,5; peptona - 2,0; $\mathrm{MgSO}_{4}-0,5 ; \mathrm{K}_{2} \mathrm{HPO}_{4}-0,87$; $\mathrm{KCl}-0,3 ; \mathrm{CaCl}_{2}-0,29$ e traços de metais $\left(\mathrm{ZnO}-2,5 \times 10^{-3}\right.$; $\mathrm{FeCl}_{3} \cdot 6 \mathrm{H}_{2} \mathrm{O}-2,7 \times 10^{-2} ; \mathrm{MnCl}_{2} \cdot 4 \mathrm{H}_{2} \mathrm{O}-1,0 \times 10^{-2} ; \mathrm{CuCl}_{2} \cdot 2 \mathrm{H}_{2} \mathrm{O}$ $-8,5 \times 10^{-4} ; \mathrm{CoCl}_{2} \cdot 6 \mathrm{H}_{2} \mathrm{O}-2,4 \times 10^{-3} ; \mathrm{NiCl}_{3} \cdot 6 \mathrm{H}_{2} \mathrm{O}-2,5 \times 10^{-4}$; $\left.\mathrm{H}_{3} \mathrm{BO}_{3}-3,0 \times 10^{-4} \mathrm{e} \mathrm{Na}_{2} \mathrm{MoO}_{4}-1,0 \times 10^{-3}\right)$. O pH foi ajustado para 7,5 com $\mathrm{NaOH}$ e este meio foi esterilizado em autoclave a $121 \pm 2{ }^{\circ} \mathrm{C}$ por 15 minutos.

O meio de cultura foi inoculado com $1 \mathrm{~mL}$ de uma cultura preparada de véspera (pré-inóculo) e incubada em um agitador rotatório (Thermo Forma Orbital Shaker, Ohio, USA) operando a $180 \mathrm{rpm}$ em temperatura de $50^{\circ} \mathrm{C}$. Em todos os experimentos foram realizadas três repetições, sendo cada uma constituída por $25 \mathrm{~mL}$ de meio de cultura em erlenmeyer de $250 \mathrm{~mL}$. Em intervalos de tempo determinados, foram retirados frascos para medida da densidade ótica a $600 \mathrm{~nm}$, com a utilização de um espectrofotômetro SHIMADZU modelo UV-mini 1240 (Kyoto, Japão), do pH e dosagem da atividade da enzima nos filtrados da cultura.

\subsection{Determinação da atividade enzimática}

Para a remoção das células, o meio de cultura foi centrifugado a 1800 g por 15 minutos a $4^{\circ} \mathrm{C}$ em uma centrífuga, modelo Hermle-Z 382K (Wehingen, Alemanha), e o sobrenadante livre de células utilizado para dosagem da atividade da amilase. A atividade enzimática foi determinada em amostras em triplicata, pela quantificação de açúcares redutores (glicose) através do método de Miller (1959).

Uma mistura contendo $0,5 \mathrm{~mL}$ da preparação enzimática (sobrenadante livre de células), $0,5 \mathrm{~mL}$ da solução de amido, 0,5\% em tampão Tris- $\mathrm{HCl} 0,05 \mathrm{M}, \mathrm{pH} 8,5$ e 0,2 mL do mesmo tampão foi incubada a $90^{\circ} \mathrm{C}$ por 10 minutos. Após este período a reação foi paralisada pela adição de $1 \mathrm{~mL}$ do reagente de Miller (1959). A mistura foi colocada em água em ebulição por 10 minutos, e em seguida resfriada em banho de gelo. A coloração desenvolvida foi medida em espectrofotômetro SHIMADZU UV-mini 1240 (Kyoto, Japão), em 540 nm. O mesmo procedimento foi realizado com o controle, exceto que o reagente de Miller foi adicionado juntamente com a enzima à solução de amido 5 g.L $\mathrm{L}^{-1} \mathrm{e}$ esta mistura foi colocada em água em 
ebulição como descrito anteriormente. Uma unidade da atividade da enzima (U) foi definida como a quantidade de enzima necessária para produzir $1 \mu \mathrm{mol}$ de açúcar redutor por minuto a partir do amido solúvel nas condições do ensaio.

\subsection{Efeito das condições de cultivo sobre a atividade da enzima}

A influência da fonte de carbono sobre o crescimento do microrganismo e a atividade da amilase foi investigada substituindo o amido solúvel do meio de cultura pelas seguintes fontes de carbono a 5 g.L. $\mathrm{L}^{-1}: \mathrm{D}(+)$ galactose, lactose, sacarose, maltose, $\mathrm{D}(+)$ glicose. Além disso, várias concentrações de amido (2,5, 5, 10 e 30 g.L. $\mathrm{L}^{-1}$ ) foram utilizadas no meio para avaliar a atividade da enzima. As fontes de nitrogênio incluindo citrato de amônio (10 g.L $\left.\mathrm{L}^{-1}\right), \mathrm{NH}_{4} \mathrm{NO}_{3}\left(10\right.$ g.L $\left.\mathrm{L}^{-1}\right),\left(\mathrm{NH}_{4}\right)_{2} \mathrm{SO}_{4}\left(10\right.$ g.L. $\left.\mathrm{L}^{-1}\right)$, $\mathrm{NH}_{4} \mathrm{Cl}\left(10\right.$ g.L $\left.\mathrm{L}^{-1}\right), \mathrm{KNO}_{3}(10$ g.L.- $)$, peptona $\left(1\right.$ a 5 g.L $\left.\mathrm{L}^{-1}\right)$, extrato de levedura $\left(2\right.$ g.L. $\left.\mathrm{L}^{-1}\right)$, extrato de carne $\left(2 \mathrm{~g} . \mathrm{L}^{-1}\right)$ e caseína $\left(2\right.$ g.L $\left.\mathrm{L}^{-1}\right)$ foram acrescidas individualmente ao meio de cultura para avaliar a atividade enzimática. Finalmente, a concentração da proteína do soro de leite também foi variada no meio de cultura de 0,25 a 1 g.L.- .

O efeito da temperatura de incubação e do $\mathrm{pH}$ inicial do meio de cultura sobre a atividade da enzima foi estudado cultivando o microrganismo nas temperaturas de 42,50 e $55^{\circ} \mathrm{C}$ e com valores iniciais de $\mathrm{pH}$ do meio entre 7 a 8,5. Os valores de $\mathrm{pH}$ do meio foram ajustados com carbonato de sódio $\left(10\right.$ g.L $\left.\mathrm{L}^{-1}\right)$.

\subsection{Hidrólise de várias fontes de amido}

A hidrólise de várias fontes de amido foi realizada de acordo com a metodologia descrita por Mamo e Gessesse (1999), com ligeiras modificações. Uma mistura contendo $100 \mathrm{mg}$ de amido, $2 \mathrm{~mL}$ da preparação enzimática $\left(100 \mathrm{U} \cdot \mathrm{mL}^{-1}\right)$ e $8 \mathrm{~mL}$ de tampão Tris- $\mathrm{HCl}(50 \mathrm{mM}) \mathrm{pH} 8,5$ foi incubada a temperaturas de 60 e $70^{\circ} \mathrm{C}$. A quantidade de açúcar redutor liberado foi determinada através do método de Miller (1959). Uma curva padrão de glicose foi construída medindo-se a absorvância de soluções com concentrações conhecidas deste açúcar a $540 \mathrm{~nm}$.

\subsection{Análise estatística}

Os experimentos foram conduzidos em triplicata e os resultados avaliados pela análise de variância (ANOVA) utilizando o programa SAS. Os efeitos dos tratamentos foram comparados pelo teste de Tukey.

\section{Resultados e discussão}

\subsection{Perfil do crescimento do microrganismo e atividade da amilase}

O Bacillus sp. SMIA- 2 cresceu e secretou amilases quando cultivado num meio de cultura contendo amido solúvel ( 5 g.L $\left.\mathrm{L}^{-1}\right)$ e suplementado com peptona ( 2 g.. $\left.\mathrm{L}^{-1}\right)$ e proteínas do soro de leite $\left(0,5\right.$ g. $\left.\mathrm{L}^{-1}\right)$ (Figura 1$)$. O crescimento exponencial do microrganismo foi observado por um período de tempo relativamente curto, iniciando após 4 horas de crescimento e finalizando

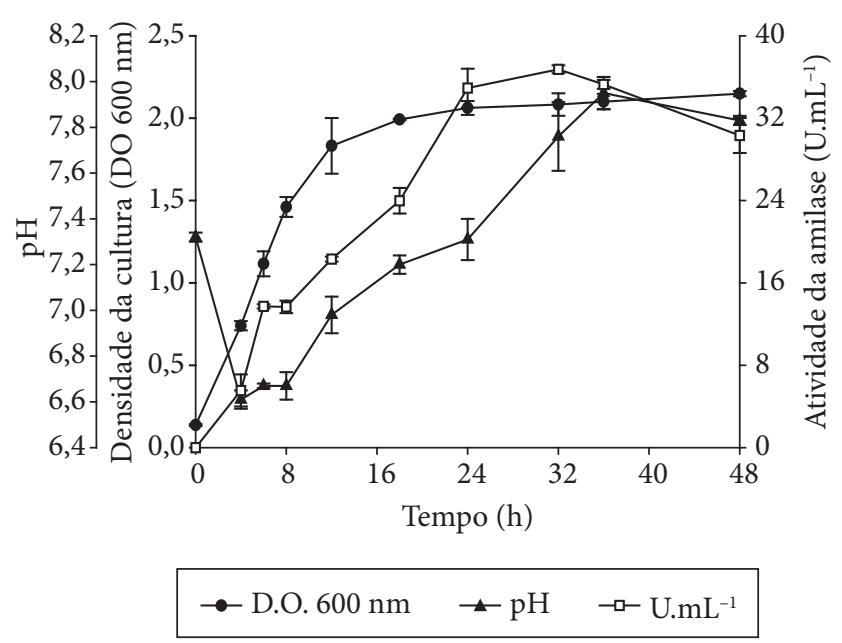

Figura 1. Crescimento e atividade de $\alpha$-amilase secretada por Bacillus sp. SMIA- 2 cultivado em amido solúvel ( 5 g.L $\left.\mathrm{L}^{-1}\right)$ e suplementado com proteínas de soro de leite $\left(0,5\right.$ g.L $\left.\mathrm{L}^{-1}\right)$ e peptona $\left(2 \mathrm{~g} . \mathrm{L}^{-1}\right)$ por 48 horas a $50^{\circ} \mathrm{C}$. As barras representam o desvio padrão. A ausência de barras indica que o erro foi menor do que o símbolo.

após 12 horas. A partir deste tempo, a cultura entrou na fase estacionária. A produção da $\alpha$-amilase iniciou durante a fase exponencial de crescimento alcançando o máximo em 32 horas, com níveis de $37 \mathrm{U} \cdot \mathrm{mL}^{-1}$. Subseqüentemente, a atividade da enzima permaneceu mais ou menos a mesma até 36 horas, e então caiu para aproximadamente $30 \mathrm{U} \cdot \mathrm{mL}^{-1} \mathrm{em} 48$ horas.

De acordo com vários autores, a síntese de $\alpha$-amilase por microrganismos do gênero Bacillus, de modo geral, ocorre de duas maneiras, dependendo das condições do experimento e do microrganismo utilizado. Na primeira, a síntese da enzima acompanha o crescimento microbiano e diminui a velocidade de síntese à medida que a cultura entra na fase estacionária (BAJPAI; BAJPAI, 1989; STEPHENSON et al., 1998). Na segunda maneira, a formação da enzima é lenta durante a fase logarítmica de crescimento, seguida de um aumento da velocidade de síntese na medida em que a velocidade de crescimento diminui e atinge a fase estacionária (ASGHER et al., 2007; GOYAL; GUPTA; SONI, 2005; HAMILTON; KELLY; FOGARTY, 1999; KONSULA; LIAKOPOULOU-KYRIAKIDES, 2007; SODHI et al., 2005; TEODORO; MARTINS, 2000). Este comportamento foi o encontrado para a $\alpha$-amilase de Bacillus sp. SMIA-2.

$\mathrm{O} \mathrm{pH}$ do meio de cultivo inicialmente caiu quando o número de células aumentou, mas tão logo a produção enzimática foi iniciada o pH do meio começou a se elevar. O final da produção enzimática foi sinalizado por um ligeiro decréscimo do $\mathrm{pH}$ da cultura. De acordo com Ming Chu et al. (1992), a acidificação ou alcalinização do meio durante o crescimento de uma cultura reflete o consumo do substrato. Quando íons amônio estão sendo utilizados, o meio torna-se mais ácido e quando nitrogênio orgânico (aminoácidos e peptídeos) está sendo assimilado, o meio torna-se mais alcalino. Devido a essa relação entre a síntese de $\alpha$-amilase e a utilização de compostos nitrogenados, a variação do $\mathrm{pH}$ é utilizada para fornecer 
informações importantes sobre a produção de $\alpha$-amilase como o início e o final de sua síntese.

\subsection{Influência da composição do meio de cultura sobre a atividade da $\alpha$-amilase}

A atividade de $\alpha$-amilase variou significativamente em resposta à fonte de carbono utilizada no meio de cultura para o crescimento do microrganismo. A produção da amilase foi significativamente maior durante o crescimento do microrganismo em amido do que em glicose (Tabela 1). Resultados semelhantes foram obtidos quando outros açúcares solúveis, tais como galactose, lactose, sacarose e maltose foram utilizados.

De fato, há uma tendência de polissacarídeos como amido solúvel, dextrina e glicogênio proporcionarem uma maior produção da enzima por microrganismos do gênero Bacillus do que mono ou dissacarídeos como glicose, frutose, lactose, galactose e sacarose. Não se sabe, no entanto, se nesses casos são os polissacarídeos adicionados ao meio de cultura em si, ou se são seus produtos de degradação ou metabólitos formados durante a fermentação, que estimulam a síntese da enzima.

Saxena et al. (2007), estudando o efeito de diferentes fontes de carbono sobre a produção de $\alpha$-amilase por Bacillus sp. PN5, verificaram que o amido induziu a síntese da enzima enquanto que a frutose e a glicose inibiram sua produção. A secreção de amilases em meios de cultivo contendo amido como fonte de carbono tem sido descrita para várias cepas de Bacillus (AGRAWAL et al., 2005; CHERRY; HUSSAIN; ANWAR, 2004; KONSULA; LIAKOPOULOU-KYRIAKIDES, 2007; MESSAOUD et al., 2004; TANYILDIZI; ÖZER; ELIBOL, 2005).

A biossíntese da amilase foi favorecida quando baixas concentrações de amido foram utilizadas no meio de cultura (Tabela 2). Embora o Bacillus sp. SMIA-2 crescesse satisfatoriamente em todas as concentrações testadas, a concentração de 2,5 g.L. $\mathrm{L}^{-1}$ foi a que proporcionou uma melhor atividade da enzima. Além disso, a biossíntese da amilase parece ser independente da disponibilidade de amido no meio, uma vez que na sua ausência foram encontrados níveis moderados da atividade da enzima $\left(23,44 \mathrm{U} \cdot \mathrm{mL}^{-1}\right)$. Estes resultados são similares aos encontrados por Konsula e Liakopoulou-Kyriakides (2004) para o Bacillus subtilis.

Tabela 1. Atividade de $\alpha$-amilase de Bacillus sp. SMIA-2 cultivado em um meio acrescido individualmente de várias fontes de carbono (5 g.L $\left.\mathrm{L}^{-1}\right)$ e suplementado com proteínas do soro de leite $\left(0,5\right.$ g.L $\left.\mathrm{L}^{-1}\right)$ e peptona $\left(2 \mathrm{~g} . \mathrm{L}^{-1}\right)$ por 32 horas a $50^{\circ} \mathrm{C}$.

\begin{tabular}{ccc}
\hline $\begin{array}{c}\text { Fonte de carbono } \\
\left(5 \mathrm{~g} \cdot \mathrm{L}^{-1}\right)\end{array}$ & $\begin{array}{c}\text { Densidade ótica } \\
(600 \mathrm{~nm})\end{array}$ & $\begin{array}{c}\text { Atividade máxima da enzima } \\
\left(\mathrm{U} \cdot \mathrm{mL}^{-1}\right)\end{array}$ \\
\hline Glicose & $1,20 \pm 0,00^{\mathrm{c}}$ & $8,30 \pm 0,84^{\mathrm{c}}$ \\
Galactose & $2,13 \pm 0,20^{\mathrm{a}}$ & $15,27 \pm 3,44^{\mathrm{b}}$ \\
Maltose & $1,68 \pm 0,11^{\mathrm{b}}$ & $14,91 \pm 8,30^{\mathrm{b}}$ \\
Lactose & $0,46 \pm 0,08^{\mathrm{d}}$ & $4,59 \pm 0,36^{\mathrm{d}}$ \\
Sacarose & $1,54 \pm 0,17^{\mathrm{b}}$ & $9,51 \pm 2,97^{\mathrm{c}}$ \\
Amido & $2,08 \pm 0,07^{\mathrm{a}}$ & $35,28 \pm 0,43^{\mathrm{a}}$ \\
\hline
\end{tabular}

As médias seguidas pela mesma letra não diferem entre si, em $5 \%$ de probabilidade, pelo teste de Tukey; e \pm indica o desvio padrão.
A suplementação do meio de cultivo com proteínas do soro de leite proporcionou um aumento da produção de $\alpha$-amilase. A atividade máxima da enzima $\left(61 \mathrm{U} \cdot \mathrm{mL}^{-1}\right)$ foi obtida quando uma concentração de 0,25 g. $\mathrm{L}^{-1}$ deste resíduo foi utilizada no meio (Tabela 3).

De uma forma geral, as fontes orgânicas de nitrogênio estimularam mais o crescimento de Bacillus sp. SMIA-2 e a síntese da amilase que as inorgânicas (Tabela 4). O aumento da concentração da peptona no meio de cultura até 2 g.L $\mathrm{L}^{-1}$ resultou em um aumento do crescimento do microrganismo e da síntese da enzima.

Entretanto, embora as concentrações de peptona acima de 2 g. $\mathrm{L}^{-1}$ tenham estimulado o crescimento do microrganismo, a atividade da amilase decresceu. Estudos conduzidos por vários outros pesquisadores revelaram que as fontes orgânicas de nitrogênio foram também as melhores para o crescimento e produção de amilases por microrganismos (GOYAL; GUPTA; SONI, 2005; JIN et al., 2001; KONSULA; LIAKOPOULOU-KYRIAKIDES, 2007; KUNAMNENI; PERMAUL; SINGH, 2005; LIN; CHYAU; HSU, 1998).

A atividade da amilase variou com o $\mathrm{pH}$ inicial do meio de cultura (Tabela 5). A mais alta atividade foi alcançada em culturas cujos valores de $\mathrm{pH}$ foram crescendo de 8,0 a 8,5. Em relação à temperatura de incubação do meio, a secreção da enzima foi máxima a $50^{\circ} \mathrm{C}$ (Tabela 6).

\subsection{Hidrólise de várias fontes de amido}

A produção de açúcares redutores a partir da hidrólise de várias fontes de amido realizada a $60{ }^{\circ} \mathrm{C}$ está mostrada na

Tabela 2. Atividade de $\alpha$-amilase de Bacillus sp. SMIA-2 cultivado em um meio contendo diferentes concentrações de amido e suplementado com proteínas do soro de leite $\left(0,5\right.$ g.L $\left.\mathrm{L}^{-1}\right)$ e peptona $\left(2\right.$ g.L $\left.\mathrm{L}^{-1}\right)$ por 32 horas a $50{ }^{\circ} \mathrm{C}$.

\begin{tabular}{ccc}
\hline $\begin{array}{c}\text { Concentração de amido } \\
\left(\mathrm{g} \cdot \mathrm{L}^{-1}\right)\end{array}$ & $\begin{array}{c}\text { Densidade ótica } \\
(600 \mathrm{~nm})\end{array}$ & $\begin{array}{c}\text { Atividade máxima da } \\
\left.\text { enzima }\left(\mathrm{U}_{\mathrm{mL}}\right)^{-1}\right)\end{array}$ \\
\hline 0 & $1,18 \pm 0,00^{\mathrm{c}}$ & $23,44 \pm 4,70^{\mathrm{d}}$ \\
2,5 & $2,11 \pm 0,06^{\mathrm{b}}$ & $50,35 \pm 0,64^{\mathrm{a}}$ \\
5,0 & $2,21 \pm 0,05^{\mathrm{ab}}$ & $46,55 \pm 2,96^{\mathrm{b}}$ \\
10 & $2,25 \pm 0,05^{\mathrm{a}}$ & $30,87 \pm 0,62^{\mathrm{c}}$ \\
30 & $1,25 \pm 0,25^{\mathrm{c}}$ & $0,0^{\mathrm{e}}$ \\
\hline
\end{tabular}

As médias seguidas pela mesma letra não diferem entre si, em $5 \%$ de probabilidade, pelo teste de Tukey; e \pm indica o desvio padrão.

Tabela 3. Atividade de $\alpha$-amilase de Bacillus sp. SMIA-2 cultivado em um meio contendo amido $\left(2,5\right.$ g. $\left.\mathrm{L}^{-1}\right)$, peptona $\left(2\right.$ g. $\left.\mathrm{L}^{-1}\right)$ e diferentes concentrações de proteína do soro de leite por 32 horas a $50^{\circ} \mathrm{C}$.

\begin{tabular}{ccc}
\hline $\begin{array}{c}\text { Concentração de } \\
\text { proteína do soro de leite } \\
\left.\text { (g.L } \mathrm{L}^{-1}\right)\end{array}$ & $\begin{array}{c}\text { Densidade ótica } \\
(600 \mathrm{~nm})\end{array}$ & $\begin{array}{c}\text { Atividade máxima da } \\
\text { enzima }\left(\mathrm{U} \cdot \mathrm{mL}^{-1}\right)\end{array}$ \\
\hline 0 & $1,92 \pm 0,09^{\mathrm{a}}$ & $35,74 \pm 0,72^{\mathrm{d}}$ \\
0,25 & $1,92 \pm 0,07^{\mathrm{a}}$ & $61,20 \pm 1,77^{\mathrm{a}}$ \\
0,5 & $1,69 \pm 0,02^{\mathrm{b}}$ & $55,06 \pm 0,96^{\mathrm{b}}$ \\
0,75 & $1,60 \pm 0,06^{\mathrm{b}}$ & $48,83 \pm 0,88^{\mathrm{c}}$ \\
1,0 & $1,60 \pm 0,14^{\mathrm{b}}$ & $50,80 \pm 3,58^{\mathrm{c}}$ \\
\hline
\end{tabular}

As médias seguidas pela mesma letra não diferem entre si, em $5 \%$ de probabilidade, pelo teste de Tukey; e \pm indica o desvio padrão. 
Tabela 4. Atividade de $\alpha$-amilase de Bacillus sp. SMIA-2 cultivado em um meio contendo amido (2,5 g. $\left.\mathrm{L}^{-1}\right)$, proteínas do soro de leite $\left(0,25 \mathrm{~g} . \mathrm{L}^{-1}\right)$ e acrescido individualmente de várias fontes de nitrogênio por 32 horas a $50{ }^{\circ} \mathrm{C}$.

\begin{tabular}{|c|c|c|}
\hline Fontes de nitrogênio (g. $\mathrm{L}^{-1}$ ) & $\begin{array}{l}\text { Densidade ótica } \\
(600 \mathrm{~nm})\end{array}$ & $\begin{array}{l}\text { Atividade máxima } \\
\text { da enzima }\left(U \cdot \mathrm{mL}^{-1}\right)\end{array}$ \\
\hline Sem nitrogênio & $0,95 \pm 0,01^{\mathrm{e}}$ & $29,93 \pm 3,43^{e}$ \\
\hline Peptona $(1,0)$ & $1,75 \pm 0,18^{\mathrm{bcd}}$ & $29,82 \pm 3,07^{\mathrm{e}}$ \\
\hline Peptona $(2,0)$ & $1,94 \pm 0,17^{\mathrm{abc}}$ & $63,53 \pm 2,82^{\mathrm{a}}$ \\
\hline Peptona $(3,0)$ & $2,02 \pm 0,13^{\mathrm{ab}}$ & $48,88 \pm 2,86^{\mathrm{b}}$ \\
\hline Peptona $(4,0)$ & $2,05 \pm 0,15^{\mathrm{ab}}$ & $17,31 \pm 1,66^{\mathrm{fg}}$ \\
\hline Peptona $(5,0)$ & $2,12 \pm 0,22^{\mathrm{ab}}$ & $0,0 \mathrm{~d}^{\mathrm{i}}$ \\
\hline Extrato de caseína $(2,0)$ & $1,95 \pm 0,13^{\mathrm{abc}}$ & $40,49 \pm 0,96^{c}$ \\
\hline Extrato de levedura $(2,0)$ & $1,74 \pm 0,20^{\mathrm{bcd}}$ & $38,94 \pm 4,04^{\mathrm{cd}}$ \\
\hline Caseína $(2,0)$ & $1,55 \pm 0,17^{\mathrm{cd}}$ & $22,83 \pm 1,80^{\mathrm{f}}$ \\
\hline$\left(\mathrm{NH}_{4}\right)_{2} \mathrm{HPO}_{4}(10,0)$ & $1,34 \pm 0,20^{\mathrm{de}}$ & $33,23 \pm 1,45^{\mathrm{ed}}$ \\
\hline $\mathrm{KNO}_{3}(10,0)$ & $1,42 \pm 0,17^{\mathrm{d}}$ & $19,62 \pm 1,97^{\mathrm{fg}}$ \\
\hline $\mathrm{NH}_{4} \mathrm{NO}_{3}(10,0)$ & $0,35 \pm 0,01^{\mathrm{f}}$ & $14,14 \pm 0,81^{g}$ \\
\hline Citrato de amônio $(10,0)$ & $2,26 \pm 0,05^{\mathrm{a}}$ & $7,01 \pm 2,21^{\mathrm{h}}$ \\
\hline$\left(\mathrm{NH}_{4}\right)_{2} \mathrm{SO}_{4}(10,0)$ & $0,36 \pm 0,03^{f}$ & $0,0^{\mathrm{i}}$ \\
\hline $\mathrm{NH}_{4} \mathrm{Cl}(10,0)$ & $0,47 \pm 0,01^{\mathrm{f}}$ & $0,0^{\mathrm{i}}$ \\
\hline
\end{tabular}

As médias seguidas pela mesma letra não diferem entre si, em $5 \%$ de probabilidade, pelo teste de Tukey; e \pm indica o desvio padrão.

Tabela 5. Atividade de $\alpha$-amilase de Bacillus sp. SMIA- 2 cultivado em um meio contendo amido $\left(2,5\right.$ g.L $\left.\mathrm{L}^{-1}\right)$, proteínas do soro de leite $\left(0,25\right.$ g.L. $\left.\mathrm{L}^{-1}\right) \mathrm{e}$ peptona $\left(2\right.$ g. $\left.\mathrm{L}^{-1}\right)$ por 32 horas a $50^{\circ} \mathrm{C}$ e com vários valores de $\mathrm{pH}$.

\begin{tabular}{ccc}
\hline pH inicial & Densidade ótica $(600 \mathrm{~nm})$ & $\begin{array}{c}\text { Atividade máxima da } \\
\text { enzima }\left(U \cdot \mathrm{mL}^{-1}\right)\end{array}$ \\
\hline 7,0 & $1,44 \pm 4,00^{\mathrm{e}-3 \mathrm{~b}}$ & $28,88 \pm 2,150^{\mathrm{c}}$ \\
7,5 & $1,66 \pm 0,02^{\mathrm{a}}$ & $34,90 \pm 0,81^{\mathrm{b}}$ \\
8,0 & $1,70 \pm 0,01^{\mathrm{a}}$ & $54,78 \pm 1,06^{\mathrm{a}}$ \\
8,5 & $1,61 \pm 9,00^{\mathrm{e}-3 \mathrm{ab}}$ & $57,70 \pm 0,59^{\mathrm{a}}$
\end{tabular}

As médias seguidas pela mesma letra não diferem entre si, em $5 \%$ de probabilidade, pelo teste de Tukey; e \pm indica o desvio padrão.

Tabela 6. Atividade de $\alpha$-amilase de Bacillus sp. SMIA- 2 cultivado em um meio contendo amido (2,5 g. $\left.\mathrm{L}^{-1}\right)$, proteínas do soro de leite $\left(0,25\right.$ g. $\left.\mathrm{L}^{-1}\right)$ e peptona $\left(2\right.$ g. $\left.\mathrm{L}^{-1}\right)$ por 32 horas a várias temperaturas de incubação e com pH 8,5.

\begin{tabular}{ccc}
\hline Temperatura $\left({ }^{\circ} \mathrm{C}\right)$ & D.O $(600 \mathrm{~nm})$ & $\begin{array}{c}\text { Atividade máxima da } \\
\text { amilase }\left(\mathrm{U}_{\mathrm{mL}}^{-1}\right)\end{array}$ \\
\hline 42 & $1,941 \pm 0,003^{\mathrm{a}}$ & $20,707 \pm 1,175^{\mathrm{b}}$ \\
50 & $2,042 \pm 0,013^{\mathrm{a}}$ & $53,203 \pm 4,319^{\mathrm{a}}$ \\
55 & $1,290 \pm 0,080^{\mathrm{b}}$ & $19,069 \pm 1,398^{\mathrm{c}}$ \\
\hline
\end{tabular}

As médias seguidas pela mesma letra não diferem entre si, em $5 \%$ de probabilidade, pelo teste de Tukey; e \pm indica o desvio padrão.

Figura 2a. Uma maior quantidade de açúcares redutores foi liberada a partir do amido de batata, seguido do amido solúvel e de mandioca, enquanto o amido de milho foi hidrolisado em uma menor extensão. A utilização do sobrenadante livre de células como fonte da enzima é altamente vantajosa, principalmente porque diminui o custo da hidrólise (KONSULA; LIAKOPOULOU-KYRIAKIDES, 2004).

A hidrólise dos vários amidos foi também realizada a $70^{\circ} \mathrm{C}$. Como pode ser visto na Figura $2 \mathrm{~b}$, a quantidade de açúcares re-
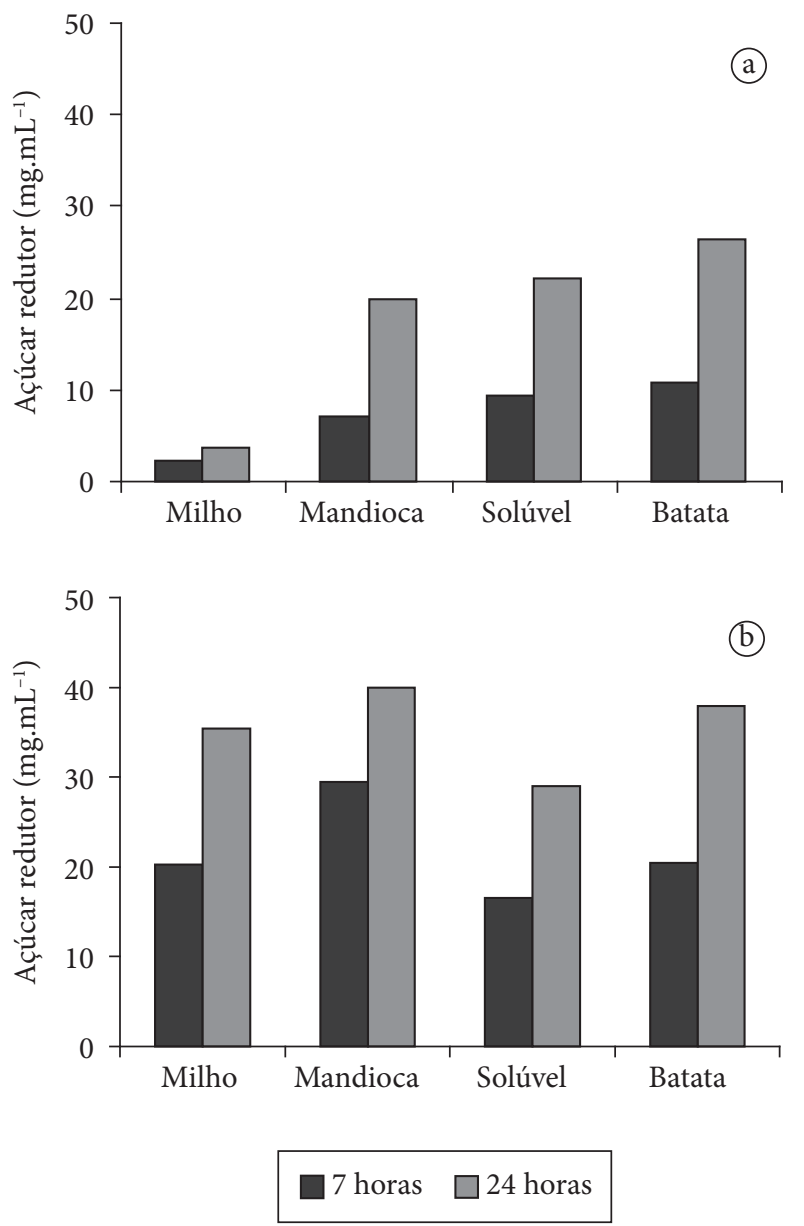

Figura 2. Produção de açúcares redutores: a) $60^{\circ} \mathrm{C}$; e b) $70^{\circ} \mathrm{C}$ a partir de diversos amidos.

dutores liberados para todos os amidos testados foi maior com o aumento da temperatura de 60 para $70^{\circ} \mathrm{C}$. Entretanto, o efeito da temperatura na extensão da hidrólise foi mais acentuado no caso do amido de milho e de mandioca. A quantidade de açúcares redutores liberados a partir da hidrólise do amido de milho e de mandioca realizada a $70{ }^{\circ} \mathrm{C}$ foi em torno de 10 e 2 vezes maior, respectivamente, que quando realizada a $60^{\circ} \mathrm{C}$. De acordo com Konsula e Liakopoulou-Kyriakides (2004), o aumento da temperatura de hidrólise geralmente provoca uma maior produção de açúcares redutores. Este aumento pode ser devido à maior atividade da enzima a altas temperaturas ou o intumescimento da região amorfa do grânulo de amido.

Goyal et al. (2005) também observaram a hidrólise substancial dos grânulos de amido na faixa de temperaturas de 60 a $90{ }^{\circ} \mathrm{C}$, indicando a natureza termoestável da enzima. A hidrólise máxima do amido de batata $(1 \%)$ ocorreu a $70{ }^{\circ} \mathrm{C}$ com 90 e $89 \%$ de conversão à glicose, após 5 e 3 horas, respectivamente.

\section{Conclusões}

A maior atividade de $\alpha$-amilase secretada por Bacillus sp. SMIA-2 é obtida quando o mesmo é cultivado em um meio 
contendo baixa concentração de amido como fonte de carbono $\left(2,5\right.$ g. $\left.\mathrm{L}^{-1}\right)$ e suplementado com 0,5 g. $\mathrm{L}^{-1}$ de proteína do soro de leite e 2 g. $\mathrm{L}^{-1}$ de peptona a $50^{\circ} \mathrm{C}$ e $\mathrm{pH} 8,5$. A enzima é capaz de degradar vários tipos de amido, sendo que a hidrólise do amido de batata resulta num alto rendimento de açúcares redutores em comparação às outras fontes de amido. $\mathrm{O}$ aumento da temperatura de reação da hidrólise para $70^{\circ} \mathrm{C}$ proporciona a obtenção de maiores quantidades de açúcares redutores.

\section{Agradecimentos}

Os autores agradecem à FAPERJ (Fundação de Amparo à Pesquisa do Estado do Rio de Janeiro) pelo apoio financeiro.

\section{Referências bibliográficas}

AGRAWAL, M. et al. Hydrolysis of starch by amylase from Bacillus sp. KCA102: a statistical approach. Process Biochemistry., v. 40, n. 7, p. 2499-2507, 2005.

ALI, S.; HOSSAIN, Z. Characteristics of glucoamylase from Aspergillus terrus. Journal of Applied Bacteriology, v. 71, n. 2, p. 144-146, 1991.

ASGHER, M. et al. A thermostable $\alpha$-amylase from a moderately thermophilic Bacillus subtilis strain for starch processing. Journal of Food Engineering, v. 79, n. 9, p. 950-955, 2007.

BAJPAI, P.; BAJPAI, P. High-temperature alkaline $\alpha$-amylase from Bacillus licheniformis TCRDC-B13. Biotechnology Bioengineering, v. 33, n. 1, p. 72-78, 1989.

BERNHARDSDOTTER, E. C. M. J. et al. Enzymic properties of an alkaline chelator-resistant $\alpha$-amylase from an alkaliphilic Bacillus sp. isolate L1711. Process Biochemistry, v. 40, n. 7, p. 2401-2408, 2005.

BOCCHINI, D. A. et al. Use of sugarcane bagasse and grass hydrolysates as carbon sources for xylanase production by Bacillus circulans D1 in submerged fermentation. Process Biochemistry, v. 40, n. 12, p. 3653-3659, 2005.

CHERRY, H. M.; HUSSAIN, T.; ANWAR, M. N. Extracellular glucoamylase from the isolate Aspergillus fumigatus. Pakistan Journal of Biology Science, v. 7, n. 10, p. 1988-1992, 2004.

DEMIRKAN, E. S. et al. $\alpha$-Amylase from B. amyloliquefaciens: purification, characterization, raw starch degradation and expression in E. coli. Process Biochemistry, v. 40, n. 8, p. 2629-2636, 2005.

DJEKRIF-DAKHMOUCHE, S. et al. Application of a statistical design to the optimization of culture medium for $\alpha$-amylase production by Aspergillus niger ATCC 16404 grown on orange waste powder. Journal of Food Engineering, v. 73, n. 2, p. 190-197, 2006.

GOSH, A.; CHATTERJEE, B.; DAS, A. Purification and characterization of glucoamylase of Aspergillus terrus NA-170 mutant. Journal of Applied Bacteriology, v. 71, n. 2, p. 162-169, 1991.

GOYAL, N.; GUPTA, J. K.; SONI, S. K. A novel raw starch digesting thermostable $\alpha$-amylase from Bacillus sp. I-3 and its use in the direct hydrolysis of raw potato starch. Enzyme Microbial Technology, v. 37, n. 7, p. 723-734, 2005.

GUPTA, R. et al. Microbial $\alpha$-amylases: a biotechnological perspective. Process Biochemistry, v. 38, n. 11, p. 1599-1616, 2003.

HAMILTON, L. M.; KELLY, C. T.; FOGARTY, W. M. Production and properties of the raw starch-digesting $\alpha$-amylase of Bacillus sp. IMD 435. Process Biochemistry, v. 35, n. 1, p. 27-31, 1999.
HAQ, I. et al. Pearl millet, a source of alpha-amylase production by Bacillus licheniformis. Bioresource Technolology., v. 96, n. 10, p. 1201-1204, 2005.

Production of alpha-amylase by Bacillus licheniformis using an economical medium. Bioresource Technology, v. 87, n. 1, p. 57-61, 2003.

JIN, F. et al. Thermostable $\alpha$-amylase and $\alpha$-galactosidase production from the thermophilic and aerobic Bacillus sp. JF strain. Process Biochemistry, v. 36, n. 6, p. 559-564, 2001.

JOO, H. S.; CHANG, C. S. Production of protease from a new alkalophilic Bacillus sp. I-312 grow on soybean meal: optimization and some properties. Process Biochemistry, v. 40, n. 3-4, p. 1263-1270, 2005.

KILIKIAN, B. V. Production of glucoamylase by fed-batch culture of Aspergillus awamori NRRL 3112. Revista de Microbiology, v. 27, n. 2, p. 137-141, 1996.

KONSULA, Z.; LIAKOPOULOU-KYRIAKIDES, M. Hydrolysis of starches by the action of an $\alpha$-amylase from Bacillus subtilis. Process Biochemistry, v. 39, n. 2, p. 1745-1749, 2004.

Co-production of $\alpha$-amylase and $\beta$-galactosidase by Bacillus subtilis in complex organic substrates. Bioresource Technology, v. 98, n. 1, p. 150-157, 2007.

KUMAR, C. G.; TAKAGI, H. Research review paper microbial alkaline proteases: from a bioindustrial viewpoint. Biotechnology Advanced, v. 17, n. 4, p. 561-594, 1999.

KUNAMNENI, A.; PERMAUL, K.; SINGH, S. Amylase production in solid state fermentation by the thermophilic fungus Thermomyces lanuginosus. Journal of Bioscience and Bioengineering, v. 100, n. 2, p. 168-171, 2005.

LIN, L. L.; CHYAU, C. C.; HSU, W. H., Production and properties of a raw starch-degrading amylase from the thermophilic and alkalophilic Bacillus sp. TS-23. Biotechnology Applied and Biochemistry, v. 28, n. 1, p. 61-68, 1998.

MAMO, G.; GESSESSE, A. Purification and characterization of two raw starch degrading thermostable $\alpha$-amylase from a thermophillic Bacillus. Enzyme Microbiology Technology, v. 25, n. 3, p. 433-438, 1999.

MESSAOUD, E. B. et al. Purification and properties of a maltoheptaose - and maltohexaose-forming amylase produced by Bacillus subtilis US116. Enzyme Microbiology Technology, v. 34, n. 6, p. 662-666, 2004.

MILLER, G. L. Use of dinitrosalicylic acid reagent for determination of reducing sugars. Analytical Chemistry, v. 3, n. 5, p. 426-428, 1959.

MING CHU, I.; LEE, C.; LI, T. S. Production and degradation of alkaline protease in batch cultures of Bacillus subtilis ATCC 14416. Enzyme Microbiology Technology, v. 14, n. 6, p. 755-761, 1992.

NASCIMENTO, W. C. A.; MARTINS, M. L. L. Production and properties of na extracellular protease from thermophilic Bacillus sp. Brazilian Journal of Microbiology, v. 35, n. 1, p. 91-96, 2004.

NGUYEN, Q. D. et al. Purification and characterisation of amylolytic enzymes from thermophilic fungus Thermomyces lanuginosus strain ATCC 34626. Enzyme Microbiology Technology, v. 31, n. 3, p. 345-352, 2002.

NIELSEN, J. E.; BORCHERT, T. V. Protein engineering of bacterial $\alpha$-amylases. Biochimistry Biophysic Acta, v. 1543, n. 2, p. 253-74, 2000.

NUNES, A. S.; MARTINS, M. L. L. Isolation, properties and kinetics of growth of a thermophilic Bacillus. Brazilian Journal of Microbiology, v. 32, n. 2, p. 271-275, 2001. 
PANDEY, A. et al. Enzyme Technology. 1 ed. New Delhi: Asiatech Publishers, Inc, 2005. 760 p.

PEDERSEN, H.; NIELSEN, J. The influence of nitrogen sources on the $\alpha$-amylase productivity of Aspergillus oryzae in continuous cultures. Applied Microbiology Biotechnology, v. 53, n. 3, p. 278-281, 2000 .

PEIXOTO, S. C. et al. Rhizopus microsporus var. rhizopodiformis: a thermotolerant fungus with potential for production of thermostable amylases. International Microbiology, v. 6, n. 3, p. 269-273, 2003.

ROMERO, F. J. et al. Production purification and partial characterization of two extracellular proteases from Serratia marcessens grow in whey. Process Biochemistry, v. 36, n. 5, p. 507-515, 2001.

SAJEDI, R. H. et al. A Ca-independent $\alpha$-amylase that is active and stable at low $\mathrm{pH}$ from the Bacillus sp. KR-8104. Enzyme Microbiology Technology, v. 36, n. 7, p. 666-671, 2005.

SARIKAYA, E. et al. Comparison of degradation abilities of $\alpha$-and $\beta$-amylase on raw starch granules. Process Biochemistry, v. 35, n. 8-9, p. 711-715, 2000.

SAXENA, R. K. et al. A highly thermostable and alkaline amylase from a Bacillus sp. PN5. Bioresource Technology, v. 98, n. 2, p. 260-265, 2007.

SIDHU, G. S. et al. Strain improvement for the production of a thermostable $\alpha$-amylase. Enzyme Microbiology Technology, v. 21, n. 5 , p. 525-530, 1997.
SOCCOL, C. R. et al. Glucoamylase. In: ENZYME TECHNOLOGY. New Delhi: Asiatec Publishers Inc., 2005. p. 221-230.

SODHI, H. K. et al. Production of a thermostable $\alpha$-amylase from Bacillus sp. PS-7 by solid state fermentation and its synergistic use in the hydrolysis of malt starch for alcohol production. Process Biochemistry, v. 40, n. 3, p. 525-534, 2005.

STEPHENSON, S. et al. The influence of protein folding of late stages of the secretion of $\alpha$-amylase from Bacillus subtilis. FEBS Letters, v. 403, n. 3, p. 385-389, 1998.

SURMELY, R. et al. Hidrólise do Amido. In: CULTURAS DE TUBEROSAS AMILÁCEAS LATINO AMERICANAS. 2003. v. 3, cap. 15. p. 377-395.

TANYILDIZI, M. S.; ÖZER, D.; ELIBOL, M. Optimization of a-amylase production by Bacillus sp. using response surface methodology. Process Biochemistry, v. 40, n. 7, p. 2291-2296, 2005.

TEODORO, C. E. D.; MARTINS, M. L. L. Culture conditions for the production of thermostable amylase by Bacillus sp. Brazilian Journal of Microbiology, v. 31, n. 3, p. 298-302, 2000.

USTÁRIZ, F. J. et al. Fermentation of individual proteins for protease production by Serratia marcescens. Biochemistry Engineering Journal, v. 19, n. 3, p. 147-153, 2004.

WU, J. R. et al. Beijerinckia indica L3 fermentation for the effective production of heteropolysaccharide- 7 using the dairy by product whey as medium. Process Biochemistry, v. 41, n. 2, p. 289-292, 2006. 